\title{
Contemporary female smokers in the US are younger and of lower socioeconomic status
}

\author{
A brief report of the 2008-2009 results from Sister to Sister: The Women's Heart Health \\ Foundation Registry
}

Jennifer L. Jarvie ${ }^{1}$, Yun Wang ${ }^{2}$, Caitlin E. Johnson ${ }^{3}$, JoAnne M. Foody ${ }^{3,4 *}$

\footnotetext{
${ }^{1}$ University of Colorado School of Medicine, Aurora, USA;

${ }^{2}$ Department of Biostatistics, Harvard School of Public Health, Boston, USA;

${ }^{3}$ Department of Cardiovascular Medicine, Brigham and Women's Hospital, Boston, USA;

${ }^{4}$ Harvard Medical School, Boston, USA; ${ }^{2}$ Corresponding Author: jfoody@partners.org
}

Received 2 March 2011; revised 3 May 2011; accepted 10 May 2011.

\begin{abstract}
Smoking is the most common cause of premature cardiovascular disease in women, but contemporary data is lacking. We sought to investigate the differences between female smokers and nonsmokers in the US. Methods: Using a registry of almost 19,000 women who attended free public heart screenings sponsored by Sister to Sister between 2008 and 2009 in 17 large US cities, we compared the means for lipid values, cardiometabolic measures, and differences in sociodemographic information between smokers and nonsmokers. Secondary outcomes were age and race-adjusted odds for obesity, the metabolic syndrome, hypertension, a non-HDL > $160 \mathrm{mg} / \mathrm{dl}$, and a serum glucose $\geq 126 \mathrm{mg} / \mathrm{dl}$ between smoking and nonsmoking women. Results: The final sample included 18,892 women $(49.8 \pm 14.3$ years, $37 \%$ black, and $32 \%$ white, $14 \%$ Hispanic), with 1,216 (6.4\%) current smokers. Smokers were younger than nonsmokers $(45.6 \pm 13.0$ vs $50.1 \pm 14.4$ years, $p<$ $0.001)$, with lower HDL levels (55.5 \pm 17.4 vs 58.6 $\pm 17.4, p<0.001)$, and higher triglycerides $(148.8$ \pm 103.7 vs $145.5 \pm 93, p=0.4082$ ). There were no significant differences in LDL between smokers versus nonsmokers. There were more black and white women in the smoking group. Smoking women were more likely to meet criteria for the metabolic syndrome (OR 1.22; 95\% Cl 1.00 - 1.49) and have a non-HDL > $160 \mathrm{mg} / \mathrm{dl}$ (OR 1.19; 1.01 1.39). Insurance and income data showed a significant inverse relationship between smoking prevalence and increasing household income. Conclusions: In this richly diverse sample of
\end{abstract}

women, female smokers were younger and of lower socioeconomic status than nonsmokers with significant differences in cardiometabolic risk factors.

Keywords: Cigarette Smoking; Cardiovascular Risk Factors; Women; Prevention

\section{INTRODUCTION}

Smoking is the strongest risk factor for premature cardiovascular disease (CVD) in women [1]. While it is well established that smoking triples CVD death, doubles stroke risk, and increases peripheral vascular disease 10 -fold, nearly 1 in 5 women continue to smoke [2].

While smoking rates continue to decrease in men, rates of decline in women have plateaued $[3,4]$. Reasons for the plateau are unclear and few contemporary data exist for women. Utilizing data from a richly diverse group of community-based women, we investigated the characteristics of female smokers and nonsmokers.

\section{METHODS}

\subsection{Study Sample}

The study sample included women who attended free Sister to Sister (STS) public heart screenings held annually in 17 large US cities in 2008 and 2009 (Atlanta, GA, Baltimore, MD, Boston, MA, Chicago, IL, Dallas, TX, Detroit, MI, Jacksonville, FL, Los Angles, CA, Miami, FL, St. Louis, MO, Tampa, FL, and Washington, DC held fairs in both 2008 and 2009, while Charlotte, NC, Indianapolis, IN, New York, NY, Philadelphia, PA, and Phoenix, AZ held fairs in 2008 only).

Screenings consisted of a standardized questionnaire 
assessing sociodemographic information, current smoking status as yes/no, and personal history of CVD. In addition, cardiometabolic measurements were obtained by trained healthcare professionals. Participants who attended 2009 fairs were queried regarding annual household income and insurance status.

\subsection{Outcomes}

Cardiometabolic measures included a single automated blood pressure measurement, height, weight, body mass index (BMI) calculation, and waist circumference (WC) measurement taken above the iliac crest and reported to the nearest 0.1 inch. Plasma glucose and cholesterol were measured using fingerstick technology on the Cholestech ${ }^{\circledR}$ LDX Analyzer (Hayward, CA). Cholesterol measures included total cholesterol (TC), high-density lipoprotein (HDL) cholesterol, and triglycerides (TG). Non-HDL cholesterol and low-density lipoprotein (LDL) cholesterol were calculated.

Hypertension (HTN) was defined as a systolic blood pressure $(\mathrm{SBP}) \geq 140 \mathrm{mmHg}$ and/or a diastolic blood pressure $(\mathrm{DBP}) \geq 90 \mathrm{mmHg}$. Criteria for the metabolic syndrome (MetS) were defined using the updated NCEP ATP III guidelines [5], which included 3 or more of the following: $\mathrm{WC} \geq 35$ inches, $\mathrm{TG} \geq 150 \mathrm{mg} / \mathrm{dl}$, $\mathrm{HDL}<50$ $\mathrm{mg} / \mathrm{dl}, \mathrm{SBP} \geq 130 \mathrm{mmHg}$ or $\mathrm{DBP} \geq 85 \mathrm{mmHg}$, or a fasting glucose $\geq 100 \mathrm{mg} / \mathrm{dl}$.

All forms and procedures were approved by Quorum Institutional Review Board (Seattle, WA).

\subsection{Statistical Analysis}

Descriptive and bivariate analyses were conducted to compare demographics, comorbidities, vital signs, and lab test data between smoker and non-smoker groups. Chi-square tests and Wilcoxen rank-sum tests were used for categorical variables and continuous variables, respectively. A hierarchical generalized linear model (HGLM) was developed to assess the risk difference between smoking and nonsmoking groups for each outcome measure and adjusted for age. We calculated 95\% confidence intervals (CI) for each estimate obtained from the model. A dummy variable was created in the model to represent records that had missing age, and excluded records with missing BMI, vital signs, and lab test data for each outcome measure. All statistical testing was 2-sided, at a significance level of 0.05 , and all analyses were conducted using SAS version 9.2 (SAS Institute Inc., Cary, NC).

\section{RESULTS}

Participant characteristics are listed in Table 1. The final sample included 18,892 women (mean age $49.8 \pm$ 14.3 years) with $37 \%(7,030)$ non-Hispanic black women, 32\% $(5,991)$ non-Hispanic white women, $14 \%$ $(2,665)$ Hispanic women, and $17 \%$ of women in the "other" category, which included $6 \%$ of women who

Table 1. Sister to Sister heart screening participant characteristics 2008 \& 2009.

\begin{tabular}{|c|c|c|c|c|c|}
\hline & \multicolumn{2}{|c|}{ Nonsmokers } & \multicolumn{2}{|c|}{ Smokers } & p-value \\
\hline Number of Participants (\%) & \multicolumn{2}{|c|}{$17676(93.6)$} & \multicolumn{2}{|c|}{$1216(6.7)$} & $\ldots$ \\
\hline Mean Age (SD) & \multicolumn{2}{|c|}{$50.1(14.4)$} & \multicolumn{2}{|c|}{$45.6(13.0)$} & $<0.001$ \\
\hline Sociodemographics & Total & $\%$ & Total & $\%$ & \\
\hline Non-Hispanic Black & 6529 & 36.9 & 501 & 41.2 & $\ldots$ \\
\hline Non-Hispanic White & 5577 & 31.6 & 414 & 34.1 & $\ldots$ \\
\hline Hispanic & 2491 & 14.1 & 174 & 14.3 & $\ldots$ \\
\hline Other* & 3079 & 17.4 & 127 & 10.5 & $\ldots$ \\
\hline Lab Values & Mean & SD & Mean & SD & \\
\hline Total Cholesterol (mg/dl) & 194.5 & 42.6 & 192 & 42.6 & 0.0809 \\
\hline HDL Cholesterol (mg/dl) & 58.6 & 17.4 & 55.5 & 17.4 & $<0.001$ \\
\hline LDL Cholesterol (mg/dl) & 110.1 & 36.2 & 110.4 & 36.4 & 0.8208 \\
\hline Triglycerides (mg/dl) & 145.5 & 93.0 & 148.8 & 103.7 & 0.4082 \\
\hline Non-HDL (mg/dl) & 136.9 & 41.8 & 136.8 & 43.8 & 0.9626 \\
\hline Glucose (mg/dl) & 105.5 & 31.8 & 105.9 & 27.9 & 0.7122 \\
\hline Cardiometabolic Measures & Mean & SD & Mean & SD & \\
\hline Systolic Blood Pressure (mmHg) & 126.9 & 19.7 & 125.6 & 19.9 & 0.0383 \\
\hline Diastolic Blood Pressure (mmHg) & 77.0 & 12.8 & 78.2 & 13.8 & 0.0062 \\
\hline BMI $\left(\mathrm{kg} / \mathrm{m}^{2}\right)$ & 27.9 & 6.3 & 28.1 & 6.3 & 0.2649 \\
\hline
\end{tabular}




\begin{tabular}{cccc}
\hline Waist Circumference (in) & 36.2 & 6.0 & 36.3 \\
*Other race/ethnicity includes $6 \%$ of women with race/ethnicity other than black, Hispanic, or white and $11 \%$ of women with unknown race/ethnicity. HDL $=$
\end{tabular}
high-density lipoprotein; LDL = low-density lipoprotein; BMI = body mass index; Ellipses (...) indicate test was not performed.

listed racial and ethnic backgrounds other than black, white, or Hispanic and $11 \%$ of women with unknown race/ethnicity. Of the total, 1,216 (6.4\%) were current smokers and 17,676 (93.6\%) were current nonsmokers. Smokers were significantly younger $(45.6 \pm 13.0$ years $)$ than nonsmokers $(50.1 \pm 14.4$ years $)$, with higher triglycerides $(148.8 \pm 103.7 \mathrm{mg} / \mathrm{dl}$ vs $145.5 \pm 93 \mathrm{mg} / \mathrm{dl}$, respectively), and significantly lower HDL levels (55.5 \pm $17.4 \mathrm{mg} / \mathrm{dl}$ vs $58.6 \pm 17.4 \mathrm{mg} / \mathrm{dl}$, respectively). Smokers also had a significantly lower mean systolic blood pressure compared with nonsmokers $(125.6 \pm 19.9 \mathrm{mmHg}$ vs $126.9 \pm 19.7 \mathrm{mmHg}$, respectively), but a significantly higher mean diastolic blood pressure compared with nonsmokers $(78.2 \pm 13.8 \mathrm{mmHg}$ vs $77.0 \pm 12.8 \mathrm{mmHg}$, respectively). Proportionally, there was a higher makeup of non-Hispanic black and non-Hispanic white women in the smoking group ( $41.2 \%$ and $34.1 \%$, respectively) compared with the nonsmoking group $(37.0 \%$ and $31.6 \%$, respectively).
A higher proportion of smokers were obese (35.4\%) and met criteria for the MetS (37.2\%) compared with nonsmoking women (32.6\% and $34 \%$, respectively) (data not shown). A strong relationship between age and smoking status was observed (Figure 1), such that there were more smokers among the younger age groups.

Significant differences existed in insurance status between smokers and non-smokers (Figure 2a), where only $45 \%$ of smokers had private insurance compared with $54.8 \%$ of nonsmokers, and a higher makeup of smokers were uninsured $(40.5 \%)$ or on Medicaid $(5.4 \%)$ compared with nonsmokers $(33.7 \%$ and $2.3 \%$, respectively). A significant inverse relationship was observed between female smoking prevalence and annual household income (Figure 2b).

Risk adjusted outcomes revealed smokers had a significantly higher risk of the MetS (OR 1.22; 95\% CI 1.00 - 1.49) as well as a non-HDL > $160 \mathrm{mg} / \mathrm{dl}$ (OR 1.19; 95\% CI 1.01 - 1.39) compared with nonsmokers (Table 2).

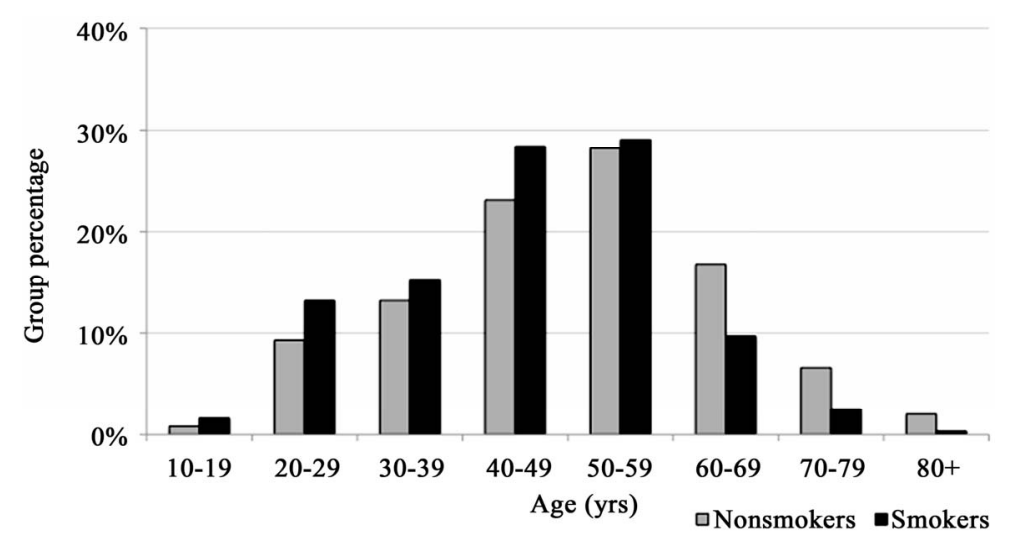

Figure 1. Smoking prevalence was higher among younger women. 


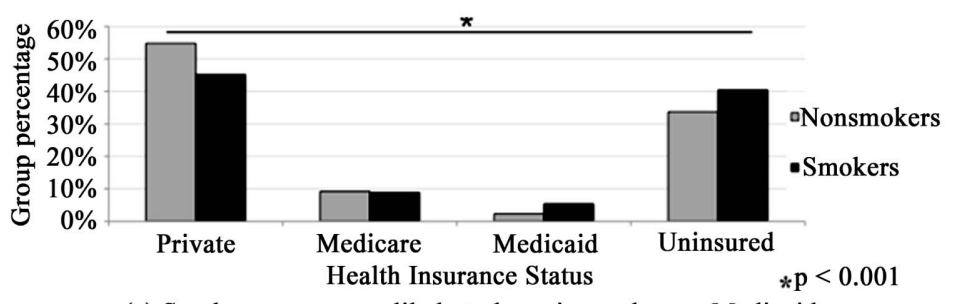

(a) Smokers were more likely to be uninsured or on Medicaid.

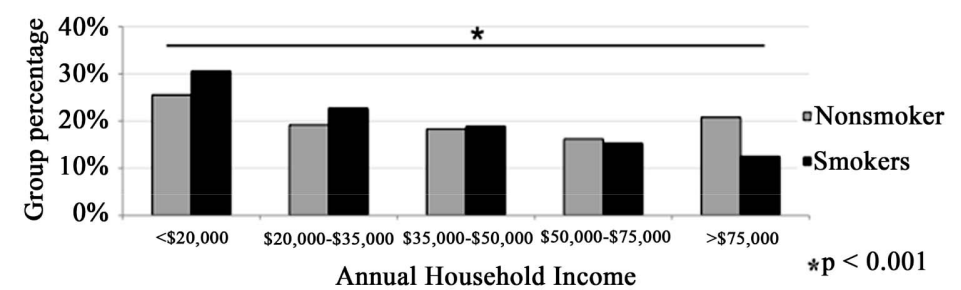

(b) Smoking prevalence declined with increasing annual household income.

Figure 2. Socioeconomic differences between smokers and nonsmokers.

Table 2. Risk adjusted outcomes in Sister to Sister women.

\begin{tabular}{cccccc}
\hline \multirow{2}{*}{ Group } & Obesity & MetS & HTN & Non-HDL $>\mathbf{1 6 0}$ & Glucose $\geq \mathbf{1 2 6}$ \\
\cline { 2 - 6 } & OR $(95 \% \mathrm{CI})$ & OR $(95 \% \mathrm{CI})$ & OR $(95 \% \mathrm{CI})$ & OR $(95 \% \mathrm{CI})$ & OR $(95 \% \mathrm{CI})$ \\
\hline Age-Adjusted & $1.00(1.00-1.01)$ & $1.02(1.02-1.03)$ & $1.04(1.04-1.05)$ & $1.02(1.02-1.03)$ & $1.03(1.02-1.03)$ \\
Nonsmoker & 1.00 (reference) & 1.00 (reference) & 1.00 (reference) & 1.00 (reference) & $1.00($ reference $)$ \\
Smoker & $1.12(0.98-1.28)$ & $1.22(1.00-1.49)$ & $1.02(0.87-1.19)$ & $1.19(1.01-1.39)$ & $1.15(0.94-1.41)$ \\
\hline
\end{tabular}

Odds ratios were drawn from a logistic model adjusted for age and race. Reference Groups: Nonsmokers reference for comparison with smokers. BMI $=$ Body Mass Index; MetS = Metabolic Syndrome; OR = Odds Ratio; $95 \%$ CI = 95\% Confidence Interval; Obesity defined as BMI $\geq 30$. MetS defined as any combination of 3 or more of the following: waist circumference $\geq 35$ in, triglycerides $\geq 150 \mathrm{mg} / \mathrm{dl}, \mathrm{HDL}<50 \mathrm{mg} / \mathrm{dl}$, SBP $\geq 130 \mathrm{mmHg}$ or DBP $\geq 85 \mathrm{mmHg}$, and/or fasting glucose $>100 \mathrm{mg} / \mathrm{dl}$.

\section{COMMENTS}

In this cross-sectional analysis of a richly diverse sample of community women in the US, smokers were younger, with lower HDL cholesterol levels, higher TG levels, and a higher proportion of women who met criteria for the MetS. The prevalence of smoking decreased with increasing annual household income, and a higher proportion of women who smoked were uninsured or on Medicaid.

Our findings are consistent with US data from the 2008 National Health Interview Survey, where prevalence of smoking was highest among adults $<65$ years of age [1]. Further, results from the Nurses' Health Study showed that women who start smoking before the age of 15 have the highest risk of CVD mortality (relative risk 9.94; 95\% CI 5.15 - 19.19) [6]. These findings illustrate the importance of aggressive smoking prevention efforts directed towards younger women given that it negates otherwise typical cardioprotection in a premenopausal woman.
Women smokers had an average HDL cholesterol 3 $\mathrm{mg} / \mathrm{dl}$ lower than nonsmoking women - translating into a $12 \%$ increased risk for CVD [7]. This was coupled with increased rates of obesity and the MetS, each increasing CVD risk. While we expected to see hyperglycemia in the smoking group given earlier reports of the association between cigarette smoke and insulin resistance [8-12], this was not the case, although increased rates of obesity and the MetS may be earlier markers.

Our overall smoking rate was notably low (6.7\%) and may be a reflection of health-seeking persons who attend health screenings. These women would be less likely to smoke or continue smoking given their concern for overall wellness, although we also captured a substantial number of women without health coverage looking for free services. Therefore, we feel our results are generalizable and our findings are consistent with previous investigations [1,13].

Although this study adds to the outdated body of literature on the differences between smokers and nonsmokers, this study does have limitations. First, while 
the majority of women attending the fair were fasting, some were not. Fasting status was recorded at the time of testing, but a non-fasting state could result in elevated glucose, TG, and LDL. Second, a single blood pressure measure was taken for most women, which may have overestimated mean blood pressure measures, although women with high readings received additional confirmatory measures, which would increase the accuracy of high findings. Third, former smoking status was not collected and many women may have been former smokers. However, cardiovascular risk drops precipitously after smoking cessation and approaches that of nonsmokers within several years $[6,14,15]$. Fourth, we were unable to account for medication use, which could have resulted in the under-estimation of HTN, hyperlipidemia, and hyperglycemic rates if controlled.

\section{CONCLUSION}

Female smokers who attended STS heart screening fairs in 2008 and 2009 were younger than nonsmokers and of lower socioeconomic status with significantly lower levels of HDL cholesterol and higher risk of the MetS. Taken together, these differences substantially increase a female smoker's risk of a cardiovascular event, and signal the need for more aggressive smoking prevention programs targeted at younger populations from lower socioeconomic neighborhoods.

\section{ACKNOWLEDGEMENTS}

We would like to thank Mrs. Irene K Pollin MSW, founder of the Sister to Sister Foundation, for her leadership and insights and her continued support for events and research that promote awareness and prevention of heart disease in women.

Dr. Foody was supported in part by a grant from the Irene and Abe Pollin Foundation and Sister to Sister: The Women's Heart Health Foundation. Dr. Jarvie was supported by the Sarnoff Cardiovascular Research Foundation, Inc.

\section{REFERENCES}

[1] Carabollo, R., Malarcher, A. and National Center for Chronic Disease Prevention and Health Promotion. (2009) Cigarette smoking among adults and trend in smoking cessation-United States, 2008. Morbidity and Mortality Weekly Report, 58, 1227-1232.

[2] Lloyd-Jones, D., Adams, R.J., Brown, T.M., et al. (2010) Heart disease and stroke statistics-2010 update: A report from the American Heart Association Statistics Committee and Stroke Statistics Subcommittee. Circulation, 121, e46-e215.

doi:10.1161/CIRCULATIONAHA.109.192667

[3] Ali, S.M., Chaix, B., Merlo, J., Rosvall, M., Wamala, S. and Lindstrom, M. (2009) Gender differences in daily smoking prevalence in different age strata: A population-based study in southern Sweden. Scandinavian
Journal of Public Health, 37,146-152. doi:10.1177/1403494808100274

[4] Tilloy, E., Cottel, D., Ruidavets, J-B., et al. (2010) characteristics of current smokers, former smokers, and secondhand exposure and evolution between 1985 and 2007. European Journal of Cardiovascular Prevention and Rehabilitation, 17, 730-736. doi:10.1097/HJR.0b013e32833a9a0c

[5] Grundy, S.M., Cleeman, J.I., Daniels, S.R., et al. (2005) diagnosis and management of the metabolic syndrome: An American Heart Association/National Heart, Lung, and Blood Institute Scientific Statement. Circulation, 112, e285-2390.

doi:10.1161/CIRCULATIONAHA.105.169405

[6] Kawachi, I., Colditz, G.A., Stampfer, M.J., et al. (1993) Smoking cessation in relation to total mortality rates in women: A prospective cohort study. Annals of Internal Medicine, 119, 992-1000.

[7] Cooney, M.T., Dudina, A., Bacquer, D.D., et al. (2009) HDL cholesterol protects against cardiovascular disease in both genders, at all ages and at all levels of risk Atherosclerosis, 206, 611-616. doi:10.1016/j.atherosclerosis.2009.02.041

[8] Ambrose, J.A. and Barua, R.S. (2004) The pathophysiology of cigarette smoking and cardiovascular disease: An update. Journal of the American College of Cardiology, 43, 1731-1737.

doi:10.1016/j.jacc.2003.12.047

[9] Craig, W.Y., Palomaki, G.E., Johnson, A.M. and Haddow, J.E. (1990) Cigarette smoking-associated changes in blood lipid and lipoprotein levels in teh 8 - 19 year old age group: A meta-analysis. Pediatrics, 85, 155-158.

[10] Eliasson, B., Mero, N., Taskinen, M-R. and Smith, U. (1997) The insulin resistance syndrome and postprandial lipid intolerance in smokers. Atherosclerosis, 129, 79-88. doi:10.1016/S0021-9150(96)06028-5

[11] Facchini, F.S., Hollenbeck, C.B., Jeppesen, J., Chen, Y-DI. and Reaven, G.M. (1992) Insulin resistance and cigarette smoking. Lancet, 339, 1128-1130. doi:10.1016/0140-6736(92)90730-Q

[12] Rafalson, L., Donahue, R.P., Dmochowski, J., et al. (2009) Cigarette smoking is associated with conversion from normoglycemia to impaired fasting glucose: The western New York study. Annals of Epidemiology, 19, 365-371.

doi:10.1016/j.annepidem.2009.01.013

[13] US Department of Health and Human Services. (2004) The health consequences of smoking: A report of the surgeon general. CDC, Atlanta.

[14] Kenfield, S.A., Stampfer, M.J., Rosner, B.A. and Colditz, G.A. (2008) Smoking and smoking cessation in relation to mortality in women. The Journal of American Medical Association, 299, 2037-2047. doi:10.1001/jama.299.17.2037

[15] Bakhru, A. and Erlinger, T.P. (2005) Smoking cessation and cardiovascular disease risk factors: Results from the third national health and nutrition examination survey. PLoS Medicine, 2, e160.

doi:10.1371/journal.pmed.0020160 